\title{
A Comprehensive Teaching Reform Model for a Computer Networks Course Based on Integrated Information Systems
}

\author{
https://doi.org/10.3991/ijet.v14i18.11040 \\ Jingmin Yang $(\bowtie)$ \\ Computer Science of Minnan Normal University, Zhangzhou, China \\ yjm4201@163. com \\ Trong-Yen Lee \\ Electronic Engineering of National Taipei University of Technology, Taipei, Taiwan \\ Baoxing Chen, Wenjie Zhang \\ Fujian Province University, Zhangzhou, China
}

\begin{abstract}
In integrating and realigning the applied skills training at Minnan Normal University (MNNU), we analyzed the current situation and problems in the teaching of the Computer Networks course based on national standards on teaching quality and the Engineering Education Accreditation standards of China. Guided by a self-developed educational management system, teaching experimentation platform and questionnaire survey system, based in a cloud computing platform, we adopted a problem-oriented research method to explore comprehensive teaching reform from four perspectives: teaching methods, teacher development, resource guarantees and continual improvement. The teaching reform cases show that the students' ability to solve problems was significantly improved, and the goal of cultivating student knowledge, ability and quality has been achieved.
\end{abstract}

Keywords-National Standards of Teaching Quality, Engineering Education Accreditation, Connotation Construction, Applied Talents, Integrated Information Systems

\section{Introduction}

In order to improve the quality assurance system in higher education computer education during the Twelfth Five Year Plan period in China, the Department of Higher Education of the Ministry of Education in China organized the Instructional Steering Committee for the Computer Specialty in Colleges and Universities to develop and issue the National Standards for Teaching Quality in the Computer Specialty in Col- 
leges and Universities ( hereinafter referred to as "Quality-Standards"): The main purpose was to standardize professional skills training requirements [1]. QualityStandards are fundamentally student-oriented principles. The orientations of the other standards were "Object Based Directed (OBD), Outcome Based Education (OBE), Capability Cultivation Directed (CCD), and Supply Requirement Directed (SRD)." Quality-Standards sought to continuously improve the quality of talent cultivation and guide reform of China's specialized teaching to meet the evolving requirements of the country's economy and society [2].

In 2016, China formally became the 18th full member state of the Washington Accord, which is a well-known international accreditation accord. The Bachelor's Degree in Engineering Education is mutually recognized among member countries of the Washington Accord. Engineering education professional certification is carried out according to internationally equivalent accreditation standards oriented toward training objectives and graduation requirements. It emphasizes core concepts focused in three ways [3]: student-centered, results-oriented and continuous improvement. The engineering education and professional qualification of graduates with a certified professional degree are accepted by other member states of the Washington Accord. It is of great significance to improve the quality of engineering education, enhance the adaptability of engineering education personnel training toward industrial development, promote international mutual recognition of engineering education in China, and enhance the international competitiveness of the engineering talent in China. In November 2017, the China Engineering Education Accreditation Association issued the "Engineering Education Accreditation Standards of China (revised in November 2017)" (hereinafter referred to as "Accreditation-Standards"), which also put forward relevant requirements for teaching reform [4].

MNNU is located in a core area of the 21 st century Maritime Silk Road and the Economic Zone on the west side of the Strait in Fujian Province in China. MNNU is responsible for serving Fujian Province's and China's demand for talent and it trains the high-quality applied managerial talent needed in the Blue Economic Pilot Area of the Taiwan Strait. Under the framework of the Quality-Standards, teaching reforms need to support the concepts and requirements of international engineering education accreditation, combined with an orientation toward applied undergraduate education, and strengthen the connotation construction. Specifically, it is necessary to refine the curriculum support for student knowledge, abilities and quality in order to meet the skills training objectives and standards, and accordingly determine the course content, reform the teaching models, improve teaching evaluations, and continuously improve the processes mentioned above [5].

Computer Networks is a basic and compulsory course in computer science for network engineering, Internet of things engineering and related majors. It is characterized as a core professional course which closely integrates computer technology and communication technology, software and hardware, theory and practice. Figure 1 demonstrates the position of the Computer Networks course within the course grouping of the network engineering specialty [6]. Practice teaching plays an important role in higher engineering education, because it is the main way of cultivating students' engineering ability, and it is also an important way to integrate theory with practice, and 
cultivate students' practical skills and problem-solving ability. In the process of such practical training, students' learning ability, communication skills, and expressive and collaborative abilities will also be rapidly improved. It is very important to explore teaching reforms that will expand these skill sets for students in the Computer Networks course.

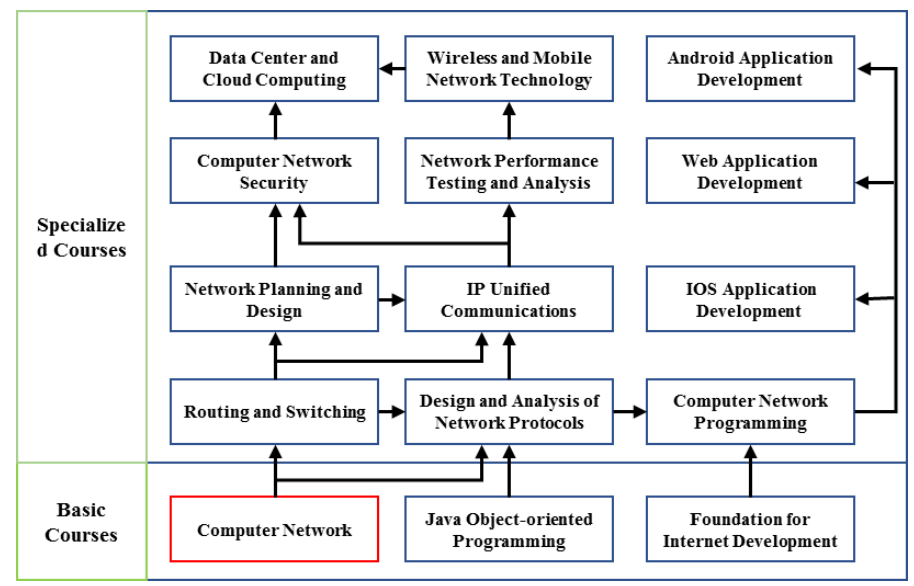

Fig. 1. Positioning of the Computer Networks course within the course grouping for the network engineering specialty.

The organization of the rest of this article is as follows: under the guidance of Quality-Standards and Accreditation-Standards, and combined with the engineering education orientation at MNNU, Section 2 analyzes the existing problems in the teaching of the Computer Networks course at MNNU via four modalities; namely, a student questionnaire survey, interviews with enterprise experts, peer review and teacher self-examination. Section 3 is problem-oriented, as it formulates the guiding principles for teaching reform, and explores comprehensive teaching reform from four perspectives: teaching methods, teacher development, resource guarantees and continuous improvement. It establishes a multi-dimensional curriculum quality assurance system, and solves the problems mentioned in the second section appropriately. Section 4 of the article summarizes the full text.

\section{Problem Analyses and Related Work}

\subsection{Problem analyses}

The Computer Science School of MNNU enrolls 1626 undergraduates across the whole school and offers four majors: Network Engineering, Internet of Things Engineering, Computer Science and Technology, and Software Engineering. Computer Networks is the basic compulsory course for all majors mentioned above. By means 
of a student questionnaire, enterprise expert interviews, teacher peer review and teacher self-examination, we collected, analyzed and classified problems in the teaching process of the Computer Networks course at MNNU. We used a weighted algorithm to score the problems. The higher the score, the more serious the problem. From the perspective of student-oriented and results-oriented principles, we weighted the problems according to student questionnaires at $30 \%$, enterprise expert interviews at $30 \%$, peer reviews at $25 \%$, and teacher self-examination at $15 \%$. A summary of the problems is shown in Table 1.

We ranked problems in descending order according to the total score for problem classification in Table 1 . The results show that the problems are mainly centered in four areas: teaching methods (415), teaching conditions and resource guarantees (185), curriculum assessment and evaluation (125), and continuous improvement (125). Specifically:

Low ability to adapt traditional teaching methods to training objectives: These problems are mainly concentrated in three areas: teaching theoretical skills, teaching practical skills and extracurricular learning. First, in teaching theoretical skills, the mode of "transfer-acceptance" is the one mainly adopted, which originated from Herbart's Five-step Teaching Method. The teacher mainly teaches through multimedia courseware and uses the blackboard as a supplementary tool; students receive information passively. The obvious shortcomings of this teaching mode in cultivating innovative thinking and the solving of problems in professional practice on the part of students have been observed. Second, the cases that teachers use in class are mainly geared toward theoretical calculations, which are lacking in computer networking engineering applications. Students generally reflect that they are often puzzled about how to apply theory into practice. In the practice part of teaching, experiments on principle verification are used primarily, and applied experiments, which cultivate engineering ability given their real-world characteristics of engineering application scenarios, are lacking, as well as comprehensive skills practice and innovative skills practice. Skills of practice teaching mainly adopts single-person and single-machine experiment mode, and lacks teamwork and collaborative training, which is not conducive to the cultivation of communication and project coordination skills where teamwork skills are needed in practical engineering projects. Skills of practice teaching are carried out following the traditional model of "principle explanation-experiment verification-teacher guidance." In practice, we find that this model has the following shortcomings: first, students are passive learners and have a poor grasp of the theory. Second, the progress of the experiments is slow. Third, teachers are busy guiding the experiment and become tired during the experiment. In extracurricular learning, the major problem is that there is no corresponding learning content designed for practical engineering development and students are forced to gather the learning materials by themselves. The students are unsupervised, which neglects the cultivation of student learning ability.

The course teaching has insufficient support for professional skills training objectives and standards: The Computer Networks course is the basic teaching unit to implement the training objectives for professional skills in Quality-Standards and Accreditation-Standards. One visualization method is to design a matrix that maps the 
curriculum to the skills training objectives and standards, which provides a basis for subsequent teaching quality evaluation and continuous improvement. The mapping matrix has not been designed yet. In addition, the foundation for engineering specialization at MNNU is relatively weak. The Network Engineering and Internet of Things majors are two new majors established in the past four years. The ratio of male to female students is close to 4:6. Students in Fujian province are the first group enrolled for college entrance examinations, while students in other provinces are the second group. The difference in the students' foundational coursework is also a key factor to be considered. Finally, students have generally reflected that the course teaching emphasizes theory and is light on practice, which is the so-called tendency in "engineering teaching theorization."

The curriculum assessment and evaluation system can be further strengthened: Currently, the course assessment mainly examines the students' academic performance through a percentage grading system, which consists of three parts: final examination score, lab score and the usual performance score, weighted at $70 \%, 15 \%$ and $15 \%$, respectively. A closed-book percentage system is adopted for the final examination score. The laboratory score is composed of written lab reports and evaluation of the experimentation process and the usual performance score is ordinarily composed mainly of students' classroom performance. Written assignments submitted by students are graded manually by teachers. Due to the large number of students and the tight number of lab courses, the students' experimentation process cannot be tracked all the way, resulting in a lack of timely evaluations and objective feedback.

The teaching resources are insufficient: Full-time teachers are engaged in teaching and theoretical research when they graduate from the university, and they lack practical experience in network engineering projects. With the growing enrollment in these courses' day by day, the basic networking laboratory is not large enough to accommodate that many students carrying out experiments at the same time. The laboratories also lack data center switches, wireless access controllers, application layer gateways and other equipment necessary for engineering practice in large- and medium-sized commercial networks, such as campus networks and enterprise networks.

The mechanism for continuous improvement of the curriculum needs to be further strengthened: Current curriculum improvement mechanisms mainly include teaching supervision by university and college supervisors, who visit and comment on classes, check teaching files and homework assessments, and analyze the quality of final examination results periodically. It is necessary to establish a closed-loop mechanism based on the teaching objectives-teaching process-learning output-teaching objectives sequence. 
Table 1. Summary of teaching problems in the computer networks course

\begin{tabular}{|c|c|c|c|c|c|c|c|}
\hline \multicolumn{2}{|r|}{ Problem } & \multicolumn{4}{|c|}{$\begin{array}{c}\text { Source and } \\
\text { Weighting of the } \\
\text { Problem }\end{array}$} & \multirow[t]{2}{*}{ IS } & \multirow[t]{2}{*}{ CS } \\
\hline Classification & Description & $S Q$ & EEI & $P R$ & $T S E$ & & \\
\hline \multirow{7}{*}{ Teaching methods } & $\begin{array}{l}1.1 \text { The traditional "transfer-acceptance" mode is adopted as the } \\
\text { main teaching method. }\end{array}$ & $\sqrt{ }$ & $\sqrt{ }$ & $\sqrt{ }$ & $\sqrt{ }$ & 100 & \multirow{7}{*}{415} \\
\hline & 1.2 Few engineering application cases are adopted in teaching. & $\sqrt{ }$ & $\sqrt{ }$ & $\sqrt{ }$ & $\sqrt{ }$ & 100 & \\
\hline & $\begin{array}{l}\text { 1.3 Principle validation experiments are for the most part in teaching } \\
\text { practical skills, lack of applied and comprehensive experiments to } \\
\text { cultivate engineering ability. }\end{array}$ & & $\sqrt{ }$ & $\sqrt{ }$ & & 55 & \\
\hline & $\begin{array}{l}\text { 1.4 Practice exercises are mainly completed by one person, which is } \\
\text { not conducive to the cultivation of teamwork spirit. }\end{array}$ & & $\sqrt{ }$ & $\sqrt{ }$ & & 55 & \\
\hline & 1.5 Lack of time leads to incomplete experiments. & $\sqrt{ }$ & & & $\sqrt{ }$ & 45 & \\
\hline & 1.6 More theoretical work and less practical work. & $\sqrt{ }$ & & & $\sqrt{ }$ & 45 & \\
\hline & $\begin{array}{l}1.7 \text { Homework plagiarism is widespread, such as program plagia- } \\
\text { rism. }\end{array}$ & & & & $\sqrt{ }$ & 15 & \\
\hline \multirow{4}{*}{$\begin{array}{l} \\
\text { Teaching Condi- } \\
\text { tions and Re- } \\
\text { source Guarantees } \\
\end{array}$} & $\begin{array}{l}\text { 2.1 Students mainly use PC and application software to carry out } \\
\text { simulation experiments, and there is a lack of equipment to carry out } \\
\text { engineering practice teaching. }\end{array}$ & & $\sqrt{ }$ & $\sqrt{ }$ & $\sqrt{ }$ & 70 & \multirow{4}{*}{185} \\
\hline & \begin{tabular}{|l|}
2.2 No open laboratory for students. \\
\end{tabular} & $\sqrt{ }$ & & $\sqrt{ }$ & & 55 & \\
\hline & 2.3 Teachers lack opportunities to improve their practical skills. & & $\sqrt{ }$ & & $\sqrt{ }$ & 45 & \\
\hline & $\begin{array}{l}\text { 2.4 Low recognition of the investment in teaching reform has } \\
\text { affected the enthusiasm of teachers. }\end{array}$ & & & & $\sqrt{ }$ & 15 & \\
\hline \multirow{2}{*}{$\begin{array}{l}\text { Course Assess- } \\
\text { ment and Evalua- } \\
\text { tion }\end{array}$} & 3.1 Curriculum evaluation is relatively simple. & & $\sqrt{ }$ & $\sqrt{ }$ & $\sqrt{ }$ & 70 & \multirow[b]{2}{*}{125} \\
\hline & $\begin{array}{l}\text { 3.2 The manner of course assessment and the method of perfor- } \\
\text { mance evaluation is single mode. }\end{array}$ & & $\sqrt{ }$ & $\sqrt{ }$ & & 55 & \\
\hline \multirow{2}{*}{$\begin{array}{l}\text { Continuous } \\
\text { improvement }\end{array}$} & $\begin{array}{l}\text { 4.1 A mapping matrix between the syllabus and skills training } \\
\text { standards is lacking. }\end{array}$ & & $\sqrt{ }$ & $\sqrt{ }$ & $\sqrt{ }$ & 70 & \multirow[t]{2}{*}{125} \\
\hline & 4.2 A continuous improvement mechanism is lacking. & & $\sqrt{ }$ & $\sqrt{ }$ & & 55 & \\
\hline
\end{tabular}

- $\quad$ Student Questionnair 30\%

- $\quad$ Enterprise Expert Interview 30\%

- Peer Review 25\%

- Teacher Self-examination $15 \%$

- Individual Score

- Classificatin Score

\subsection{Related work}

Aimed at improving the teaching quality of Computer Networks courses, according to their own characteristics and training objectives, different universities in China have carried out various forms of teaching reform and exploration, and produced a large number of innovative teaching models. Zhao Ming of China Agricultural University put forward research-based teaching [7], which integrates scientific research achievements, methods and ideas, including requirements for reading professional literature into the whole teaching process; this approach considers the cultivation of student innovation and practical abilities as the main goal of educational reform. Chen Li of Sichuan University added comprehensive experimentation content to the lab course and designed a comprehensive lab syllabus to improve students' innovation skills and sensibility and to better stimulate students' interest in experimentation [8]. Furthermore, many other teaching models integrated with new high technologies have been used to reform and improve course teaching quality in recent years. Renshu Huang of Xiamen Institute of Software Technology introduced an innovative PBL (Problem-Based Learning) teaching method and combined teacher and student inter- 
action for a networks course, while utilizing cloud computing [9]. Wenxin Xu of Fujian Normal University constructed an online learning system based on panoramic technology. This system synchronously performs the explanatory process, voice, and course data [10]. The above-mentioned curriculum reforms pay more attention to the improvement of specific teaching models or the application of new technologies, but lack the research on a comprehensive improvement model. Under the guidance of Quality-Standards and Accreditation-Standards and based on the applied skills cultivation and orientation at MNNU, this paper clarifies guidelines for teaching reforms and exploration, designs a comprehensive curriculum reform model consisting of "teaching methods, teacher development, resource guarantees, continuous improvement," and carries out reform exploration and practice. The effect of the improvements assessed with quantitative indicators is also provided.

\section{Exploration and Teaching Reform}

\subsection{Guidelines}

Explicit objective: We can clarify three objectives of the teaching curriculum: orientation toward training objectives, orientation toward school objectives, and orientation toward employer requirements. These objectives are each divided into the corresponding specific curriculum content that can be implemented. More specifically, based on the trinity model consisting of knowledge, ability and quality, a mapping matrix is built, which divides the requirements of the three objectives into specific curriculum content.

Scientific teaching: In principle, in order to ensure the effectiveness of the teaching reforms and improve the quality of teaching, we selected a mature educational theory with successful use cases that support and explore new methods of teaching reform, and optimize the practice process according to our own physical realities and conditions. On this basis, we can take advantage of the long-term experience of teaching and information systems development to explore the characteristics of information-based teaching.

Problem-oriented: First, we continued to identify problems through investigation and analysis, distinguish the prevalence and severity of the problems, grasp key problems affecting the overall situation, solve key problems accurately, and reflect objectively on the effect of educational reform with quantitative indicators. Second, we must put an end to situations where, with respect to the reform, the form is weighted more than the content. What are the specific key problems? For example, in seminar teaching, problems and cases characterized by oversimplification and lack of pertinence lead to a failure to promote students' thinking and learning in depth. In flipped teaching, the problems lie in the lack of clear guidance for students' pre-class learning.

Based on the above-mentioned guidelines, to solve the problems analyzed in Section 2, we designed a comprehensive curriculum reform model, which includes four 
components: teaching methods, teacher development, resource guarantees and continuous improvement, as shown in Figure 2.

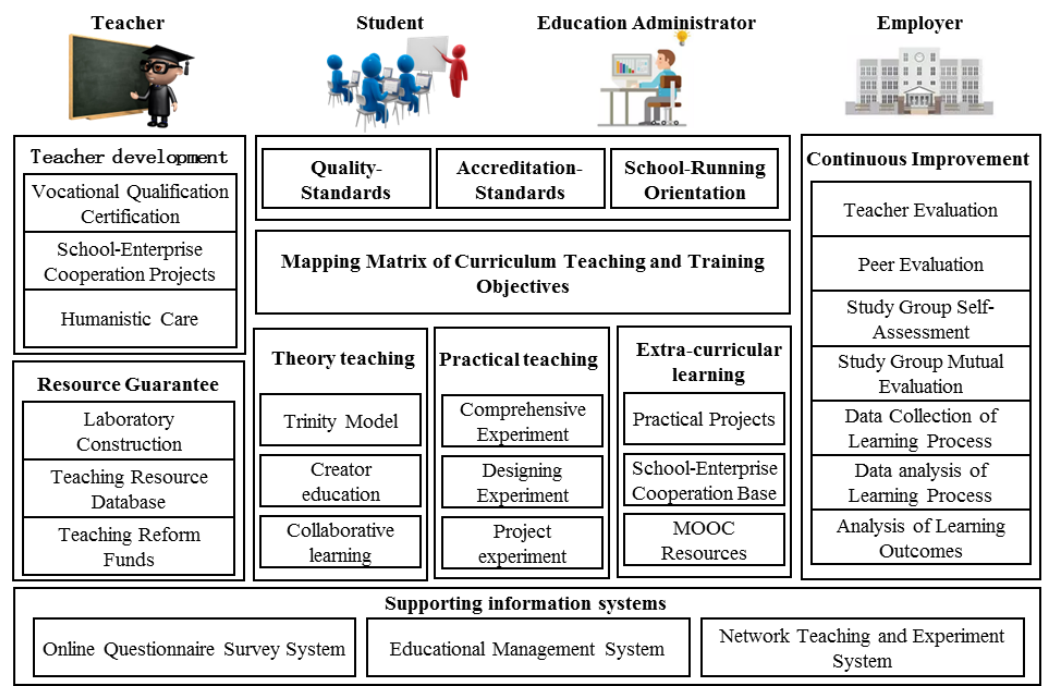

Fig. 2. Comprehensive reform model for teaching the Computer Networks course.

\subsection{Teaching methods}

Professional ability-oriented trinity teaching theory model: The Trinity Teaching model is a mature theoretical model with a large number of successful cases [11]. Based on many years of teaching practice, teachers of the network engineering teaching and research department analyzed the teaching objectives and key knowledge points to be mastered in each part of the Computer Networks course. They implemented heuristic teaching and design problems carefully to cultivate the students' ability to discover, analyze and solve problems. The problems are derived from three categories: the first category is theoretical problems, mainly coming from textbooks and teaching guide materials, and some come from the teachers' scientific research projects; the second category is engineering problems, mainly pulled from schoolenterprise cooperative projects, and some come from the teachers' enterprise-level engineering development projects; the last category is the problems raised by students. Teaching method reform pays attention to comprehensive improvement in student's learning ability, innovative abilities, communication, expressive ability and cooperative teamwork abilities. In order to achieve the above-mentioned goals better, the teachers have developed information systems to support the above pedagogical processes, including online questionnaire survey systems, educational management systems, networking teaching and experimentation platform systems. Questions and the corresponding reference answers are stored in the question database of the teaching management system, and the question database is updated every semester. 
Output-oriented maker education model: In 2001, the MIT Center for Bits and Atoms Research launched a novel research experiment: a fabrication laboratory [12], which was the origin of the Maker model. It is a new educational model developed in recent years that emphasizes "creative-based learning." Maker education is resultsoriented. Its main purpose is to cultivate applied skills with an innovative focus, mindset and skillset [13]. In September 2015, the Ministry of Education of China proposed "exploration of maker education and other new education models" [14]. In practice, the teaching and research department integrates the knowledge points of the Computer Networks course with the academic research and applied research topics of the teachers in software defined networks, cloud computing, cognitive radio, data mining, etc., and forms a comprehensive learning theme group, consisting of many independent learning topics, and these topics are undertaken by the maker learning group composed of students. Generally, about $15 \%$ of the theoretical teaching hours and $80 \%$ of extra-curricular learning are used for maker education. Evaluating the learning effect by learning output is one of the characteristics of creator education. Aimed at the group's comprehensive lab topic, the Maker Learning Group designs solutions, which are validated and improved through experiments using laboratory equipment. In the work exhibition stage, first, the Maker Learning Group demonstrates various works and reports results through PowerPoint presentations; second, interactive activities are carried out, including student questions and answers, and teacher comments. Through the above activities, excellent work and projects will stand out. These works will be entered into subject competitions, teacher project works, etc. Finally, work that is of excellent quality will be imported into the results database as reference material for the next semester. The process for the Maker Learning Group's practice activities is shown in Figure 3.

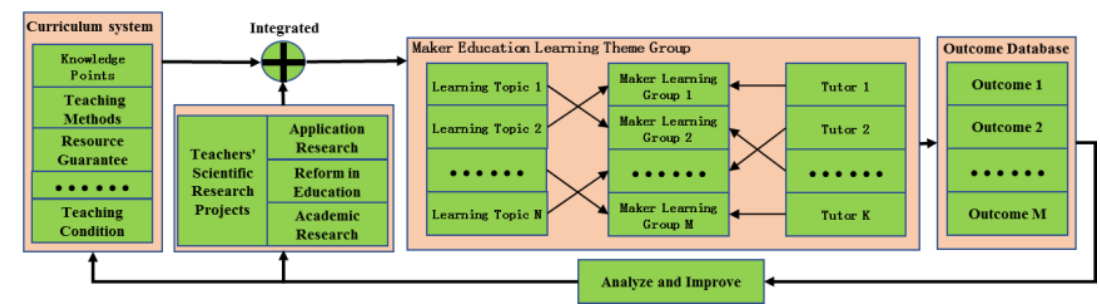

Fig. 3. Maker education practice flow chart.

In the teaching practice, students, as active learners, need to deal with three types of synergetic learning relationships: theory and practice learning, curricular and extracurricular learning, individual and team learning [6]. Because individual differences will lead to different learning progress pathways and learning effects, teachers need to follow up on each student's learning progress continuously, find problems and solve them in time. This was a difficult task before. Now, the application of information system can rapidly improve the efficiency of this process. Teachers collect and analyze the learning process of each student through the teaching management system and questionnaire system, discover the students' learning problems in specific 
knowledge modules on a timely basis, and with the push through of electronic cases, on-site counseling, classroom evaluation and other forms, carry out targeted guidance to help students solve problems. Within the scope of the campus network, students can make a lab appointment using the teaching and laboratory system through the campus network, which provides a $24 / 7$ open networking laboratory for students to carry out experiments. In the process of doing experiments, the system provides experimental verification scripts, which can help students automatically and quickly verify the experimental results, and also provide experimental configuration references, which can help students quickly grasp practical skills.

\subsection{Teacher development}

The development of "Academic-Practical" teachers characterized by high quality professional standards is an important guarantee contributing to improvement in the quality of education. In practice, in addition to attaching importance to the training and continuing education of existing professional teachers and improving their professional skills at the level of theory and practice, it was also necessary to address the motivation of teachers and stimulate their career enthusiasm. The following four practical cases are provided for reference. First, through the talent introduction policy, senior engineers with extensive experience in network equipment research \& development and IT project management were enrolled and appointed to take charge of laboratory construction and the engineering practice teaching. The addition of these engineers strengthened the applied engineering capabilities of the network engineering teaching and research department. Second, teachers were encouraged to actively apply for teaching reform projects, such as the School-Enterprise Cooperative Education Project of the Ministry of Education of China, which will offer additional points in the evaluation for academic titles and offer preferential teaching awards. Third, there was a great deal of work done behind the scenes in curriculum reform, such as developing the information system, guiding students, coming up with teaching cases and so on. This part of the behind the scenes work was identified and quantified into the workload. Spiritual encouragement was prioritized, supplemented by appropriate material rewards, so that teachers could be recognized and respected. Finally, teachers were encouraged to take qualification and competency tests related to teaching, such as the Cisco Network Engineer Certification Training and Examination. The fees for training and certification are supported by special funds for teacher development. The enthusiasm of teachers has been stimulated by the above-mentioned methods, and they actively participate in the reforms and engineering practice, so as to improve their teaching at the theoretical level and their capabilities in engineering professional practice.

\subsection{Resource guarantees}

Laboratory construction: The professional qualifications requirements of network engineers are referred to regarding best practices. We upgraded the construction of laboratories and constructed a two-level model for a "basic network laboratory- 
professional network laboratory." The purpose was to close the gap between basic skills training and professional skills training, and realize the connection between the school teaching and the enterprise engineering environment. We upgraded and expanded the basic networking laboratory in 2016, built the communication networks laboratory in 2017, purchased data center switches, core switches, application gateways, wireless controllers, wireless access points and other network equipment from Cisco, Aruba and other companies. These devices are mainly to allow students to practice with medium- and large-sized commercial networks. In addition, other related professional networking laboratories include the software defined networks laboratory and the integrated laboratory for the Internet of Things, which were constructed in 2018, and the Joint Laboratory for Industrial Control Systems Security, which will be constructed in 2019. Second, the laboratory management system was reformed and new regulations established. These new regulations not only give teachers more autonomy in the use of laboratories, but also use the quality of students' training, teaching results, and scientific research results to quantify the assessment of teachers, so as to standardize the use of laboratories and improve the teaching output of the laboratories.

Teaching resource database: The teaching resource database is the basic guarantor for smooth teaching of coursework. The perfection of the construction of the teaching resource database has a great influence on the achievement of educational goals. In a narrow sense, the teaching resource database mainly includes hardware resources and software resources. Hardware resources mainly include laboratory spaces and laboratory equipment, and software resources mainly include problem databases, teaching-case databases, micro-lecture videos, application software, simulation software, teaching materials and so on. From a broad perspective, the teaching resource database also includes social education-assistance resources. The training goal for undergraduate applied engineering students is to meet the needs of society and the stakeholders in social education-assistance include alumni, employers, network equipment manufacturers, etc. We cooperate with these stakeholders in many ways. Typical practices include employing enterprise engineers as part-time teachers, building teaching skills, and basic practical skills, etc.

Teaching reform funds: In current practice, educational reform funds mainly come from three categories: the first category is the special funds for teaching provided by the university. This kind of funding comes from the state financial allocations, which are the most common sources of funds. The second category is the teachers' project funds, mainly including scientific research funds and enterprise project development funds. The third category is the funds provided by social education-assistance resources, such as the funds from the School-Enterprise Cooperative Education Project of the Ministry of Education. The teaching reform achievements shown in Table 2 are mainly supported by the latter two funds.

Information system: Making use of information technology to innovate teaching models and methods is an important way to accelerate the deep integration of information technology and educational teaching [15]. In the course of our teaching reforms, utilizing the technical advantages of the teaching and research departments, we developed our own questionnaire system and educational management system. Based 
on the purchase of a commercial laboratory system, we have developed new components for a teaching and experimentation platform for networks, which provides $24 / 7$ online experimentation services on a reservation basis. During the construction of the communication networks laboratory in 2016, a networking teaching and experimentation platform was installed and the manufacturer provided a networking experimentation teaching function based on real networking equipment and enterprise engineering practice projects, which can be operated remotely throughout the network. On the basis of the above-mentioned functions, we proceeded to a secondary development, adding three major functions: an online booking system for the laboratory, individual and group learning spaces, and automatic verification of experimental results. Specifically, student accounts are imported into the system in batches; students are granted the corresponding authority by teachers. Students reserve laboratory equipment through the online booking function. The access IP address is limited to the campus network. In theory, the laboratory can provide $24 / 7$ online experimentation services. In practice, following the management regulations of the university, access to the area is allowed only within the student dormitory district, and the time limit for access is from 8:00 to 22:00. Individual and group learning spaces store electronic documents of the learning projects, including network topology files, configuration files, electronic textbooks and other materials, so as to facilitate continuous learning in the Maker Learning Group. The JavaScript language is used by the experimental results automatic verification system to develop the result verification scripts and the reference configuration file matching scripts. After completing an experiment, students run the result verification scripts to assist in checking the test results. Students can also run the matching scripts for the reference configuration files to find differences through comparison. The use of scripts improves the efficiency and quality of the experiments. In addition to the common functions of the educational administration management, the educational management system also has a three-level evaluation function for teachers, students and peers. The teaching evaluation indexes are designed in detail and distributed to teachers and students through the questionnaire system over the campus network. The data from teaching evaluations are collected and analyzed to improve teaching quality.

\subsection{Continuous improvement}

Teaching evaluations are an important part of teaching quality management. They have great significance in strengthening student learning and promoting teachers' professional development by constructing a scientific and rational teaching evaluation index system, which assesses the results of the teachers' theoretical teaching and engineering practice teaching objectively and fairly [16]. Before the teaching reforms, the evaluation system of the Computer Networks course was relatively simple. In order to achieve more rational evaluations, we constructed the three-level evaluation system for students, teachers and peers [17]. The new evaluation system mainly focuses on the academic nature of theoretical teaching, interaction in the teaching process, the authenticity of engineering practice, the growth of students, and the guidance of evaluation indicators. The evaluation is multi-dimensional. Taking the evaluation 
of Maker Education for example, the evaluation of the Maker Learning Group is derived from three domains: the daily assessment of teachers, the mutual evaluations of daily performance in the Maker Learning Group and the self-evaluation by group members. The works of the Creator Learning Group's comprehensive training project has the same evaluation process.

Engineering ethics is an important aspect that needs to be addressed through teacher guidance and evaluation [18]. Through education in engineering ethics, students gain strong ethical values, establish a well-honed consciousness of engineering ethics, and learn to consciously regulate their own ethical behavior in their future engineering practice, thus preventing the occurrence of ethics violations. In practice, engineering ethics education is integrated into engineering practice projects. Through the analysis of problems and cases, students establish a solid sense of engineering ethics.

\subsection{Implementation effect}

The teaching reforms for the Computer Networks course began in the second half of 2016 and continued through two academic years. The school evaluation data shows that the average score for student evaluations of their teachers reached 98.2 points, which is 8.6 percentage points higher than the previous evaluation score of 89.6 points, ranking in the top $5 \%$ in the professional group. The average score for peer reviews also reached 96.7 points, which was 6.4 percentage points higher than the previous evaluation score of 90.3 points, ranking it in the top $10 \%$ of the professional group. Among the sub-indicators in teaching evaluations, maker education and open laboratory won the highest appraisal by students, and they were 99.8 points and 98.2 points, respectively. At the same time, maker education and teacher development won the highest appraisal from the peer teaching evaluations, which were 98.5 points and 97.3 points, respectively. The outcomes of Creator Education are shown in Table 2. The outcomes show that most of the feedback problems in Section 2.1 were solved or alleviated, and the effects of the improvements are obvious.

Table 2. Output Cases from the Maker Education Practice (2017-2019)

\begin{tabular}{|c|c|c|c|c|}
\hline $\begin{array}{c}\text { Knowledge points in the } \\
\text { Computer Networks } \\
\text { Course } \\
\end{array}$ & $\begin{array}{c}\text { Teachers' Scien- } \\
\text { tific Research } \\
\text { projects }\end{array}$ & $\begin{array}{l}\text { Engineering } \\
\text { application } \\
\text { scenarios } \\
\end{array}$ & Students' works & Achievements \\
\hline $\begin{array}{l}\text { (1) Network Architecture } \\
\text { (2) Principle of the TCP } \\
\text { Protocol } \\
\text { (3) Network Programming } \\
\text { (Extension)* }\end{array}$ & $\begin{array}{l}\text { Cooperative } \\
\text { Education Project } \\
\text { of the Ministry of } \\
\text { Education }\end{array}$ & $\begin{array}{l}\text { Monitoring Net- } \\
\text { works Public } \\
\text { Opinion }\end{array}$ & $\begin{array}{l}\text { Design and Imple- } \\
\text { mentation of a Real- } \\
\text { time Public Opinion } \\
\text { Monitoring System } \\
\text { Based on Python }\end{array}$ & $\begin{array}{l}\text { (1) Third Prize in the } \\
\text { College Students } \\
\text { Artificial Intelli- } \\
\text { gence Competition } \\
\text { of Fujian Province in } \\
2017 \\
\text { (2)Project accom- } \\
\text { plishment }\end{array}$ \\
\hline $\begin{array}{l}\text { (1) IP protocol and IP } \\
\text { address planning } \\
\text { (2)Ethernet and Spanning } \\
\text { Tree Protocol } \\
\text { (3) Routing and Routing } \\
\text { Selection }\end{array}$ & $\begin{array}{l}\text { Cooperative } \\
\text { Education Project } \\
\text { of the Ministry of } \\
\text { Education }\end{array}$ & $\begin{array}{l}\text { Medium- and } \\
\text { Large-scale } \\
\text { Network Con- } \\
\text { struction }\end{array}$ & $\begin{array}{l}\text { Design and Imple- } \\
\text { mentation of an } \\
\text { Intelligent Campus } \\
\text { Network Based on } \\
\text { Artificial Intelli- } \\
\text { gence }\end{array}$ & $\begin{array}{l}\text { (1) Second Prize in } \\
\text { the Internet of } \\
\text { Things Applied } \\
\text { Skills Competition } \\
\text { of Fujian Province } \\
\text { Free Trade Zone in }\end{array}$ \\
\hline
\end{tabular}




\begin{tabular}{|c|c|c|c|c|}
\hline $\begin{array}{l}\text { (4)IPv6 } \\
\text { (5)Wireless Local Area } \\
\text { Network }\end{array}$ & & & & $\begin{array}{l}2017 \\
\text { (2)Project accom- } \\
\text { plishment }\end{array}$ \\
\hline $\begin{array}{l}\text { (1) Network Architecture } \\
\text { (2)Principle of the TCP } \\
\text { Protocol } \\
\text { (3)Network Programming } \\
\text { (Extension)* }\end{array}$ & $\begin{array}{l}\text { Cooperative } \\
\text { Education Project } \\
\text { of the Ministry of } \\
\text { Education }\end{array}$ & $\begin{array}{l}\text { Online Question- } \\
\text { naire Survey }\end{array}$ & \begin{tabular}{|l|} 
Design and Imple- \\
mentation of an \\
Online Questionnaire \\
Survey System \\
Based on PHP
\end{tabular} & $\begin{array}{l}\text { (1) Information } \\
\text { system for teaching } \\
\text { reform } \\
\text { (2)Project accom- } \\
\text { plishment }\end{array}$ \\
\hline $\begin{array}{l}\text { Network Architecture } \\
\text { (2)Principle of the TCP } \\
\text { Protocol } \\
\text { (3)Principle of the UDP } \\
\text { Protocol } \\
\text { (4) Network Management } \\
\text { (5)Principle of Software } \\
\text { Defined Network Tech- } \\
\text { nology (Extension)* }\end{array}$ & $\begin{array}{l}\text { The Special Re- } \\
\text { search Fund for } \\
\text { Higher Education } \\
\text { of Fujian province }\end{array}$ & $\begin{array}{l}\text { Configuration and } \\
\text { Management of } \\
\text { Medium and } \\
\text { Large Networks }\end{array}$ & $\begin{array}{l}\text { Network Equipment } \\
\text { Status Monitoring } \\
\text { System Based on } \\
\text { Software Defined } \\
\text { Networks }\end{array}$ & $\begin{array}{l}\text { (1) Third Prize in the } \\
\text { College Students } \\
\text { Artificial Intelli- } \\
\text { gence Competition } \\
\text { of Fujian Province in } \\
2018 \\
\text { (2)Project accom- } \\
\text { plishment }\end{array}$ \\
\hline $\begin{array}{l}\text { (1) Network Architecture } \\
\text { (2)Ethernet Technology } \\
\text { (3)IP protocol } \\
\text { (4)Cloud computing } \\
\text { architecture (extension)* } \\
\text { (5)Application of Prox- } \\
\text { mox VE Virtualization } \\
\text { Platform (Extension)* }\end{array}$ & $\begin{array}{l}\text { Enterprise Private } \\
\text { Cloud Construc- } \\
\text { tion project }\end{array}$ & $\begin{array}{l}\text { Enterprise Private } \\
\text { Cloud Construc- } \\
\text { tion }\end{array}$ & $\begin{array}{l}\text { Verification and } \\
\text { Implementation of } \\
\text { an Enterprise Private } \\
\text { Cloud Platform } \\
\text { Based on Proxmox } \\
\text { VE }\end{array}$ & $\begin{array}{l}\text { (1)Project accom- } \\
\text { plishment } \\
\text { (2) } 2 \text { utility model } \\
\text { patents }\end{array}$ \\
\hline
\end{tabular}

\section{Conclusion}

Under the guidance of MNNU's general and problem-oriented direction, the Quality-Standards and Accreditation-Standards were considered the guiding framework toward a comprehensive exploration of teaching reforms with respect to four areas: teaching methods, teacher development, resource guarantees and continuous improvement. The practical teaching results show that it achieved the requirements of the Quality-Standards and Accreditation-Standards. In the next step, we plan to deepen our students' practical skills and improve their theoretical level of expertise in the following three regards: the first is to introduce virtual reality (VR) and augmented reality (AR) technology into the experimentation platform. The basic characteristics of VR/AR technology are immersion, interaction and imagination. It treats computer technology as the core, creating a virtual environment that integrates vision, hearing and feeling, making a human, machine and the environment interact dynamically. Such an environment allows in-depth learning, and further improves the student learning experience and efficiency. The second improvement will be to use big data learning analysis technology to collect various types of data in the teaching process, establish analysis models, provide accurate learning diagnoses, and optimize learning outcomes and learning situations. In the third improvement, it will be necessary to study maker education and the development of maker spaces to further nurture and cultivate the unique culture of makers, and explore a new model of innovation and entrepreneurship education. 


\section{Acknowledgement}

This work is supported by the Natural Science Funds of China under Grant 61701213, the Cooperative Education Project of Ministry of Education under Grant 201702098015 and Grant 201702057020, the Special Research Fund for Higher Education of Fujian under Grant JK2017031, and the Zhangzhou Municipal Natural Science Foundation under Grant ZZ2018J21.

\section{$6 \quad$ References}

[1] Teaching Steering Committee for Computer Majors of Higher Education Institutions of the Ministry of Education. The National Standard for Teaching Quality of Computer Specialty in Colleges and Universities [Z].2018.

[2] Zongli Jiang. Thoughts on Developing National Standards for Teaching Quality of Computer Specialty [J]. China University Teaching, 2014(10):52-55.

[3] Qu Zhenyuan. To Promote China's Higher Engineering Education to A Higher Level [J]. Research in Higher Education of Engineering, 2017(01):18-22+29.

[4] China Engineering Education Accreditation Association. Engineering Education Accreditation Standards of China (revised in November 2017) [Z].2017. http://www.ceeaa.org.cn/main!newsView4Simple.action?menuID=01010702\&ID=100000 $\underline{607}$

[5] Xiaoqiu Shi, Zongli Jiang. Improving the Quality of Network Engineering Talents Training based on Standards and Connotation construction[J]. China University Teaching, 2016(1):30-35.

[6] Teaching Steering Committee for Computer Majors of Higher Education Institutions of the Ministry of Education. Guidelines for the Training of Applied Talents in Network Engineering Major for Undergraduates in Colleges and Universities (2016 Edition). 2016.

[7] Ming Zhao. Teaching Reform and Exploration of Computer Network Course for Undergraduates [J]. Higher Education Exploration, 2017(S1):98-99.

[8] Chen Li, Rao Jian, Sun Jieping, Ju Shenggen. Exploration on comprehensive experimental teaching of computer network under double innovation education mode [J]. 2018, No.268 (12):195-198.

[9] Renshu Huang. Development of a Cloud-based Network Teaching Platform[J]. International Journal of Emerging Technologies in Learning, Vol 13, No 04 (2018):176186.https://doi.org/10.3991/ijet.v13i04.8258

[10] Wenxin Xu, Jiwei Yao. An Online Learning System Based on Panoramic Technology for Sport Psychology[J].International Journal of Emerging Technologies in Learning,Vol 11, No 09 (2016):20-24.http://dx.doi.org/10.3991/ijet.v11i09.6115

[11] Xiaoqiu Shi, Jun Liu. Reform and Practice of "Trinity" Classroom Teaching Model [J]. China University Teaching, 2015(8):34-39.

[12] Teng, C.K., Chuang, M.C., Hsu, C.C. Planning a Design Course for Play Experience and FabLab [J]. Universal Journal of Educational Research, 2015, vol. 3(10): 751756.https://doi.org/10.13189/ujer.2015.031014

[13] He Kekang. On Maker Education and Innovation Education [J]. Educational Research, 2016(4):12-24+40. 
[14] Yunling Fu. A "Maker Education + SPOC" Teaching Model for College Political Economics Courses[J].International Journal of Emerging Technologies in Learning,Vol 14, No 03 (2019):139-150.https://doi.org/10.3991/ijet.v14i03.10103

[15] Chang Pan.A Painting Teaching Mode Based on STEM Theory[J]. International Journal of Emerging Technologies in Learning,Vol 13, No 08 (2018):159-171.https://doi.org/10.3 991/ijet.v13i08.9048

[16] Guoyu Wu, Chunyang Wang, Xiufang Peng. Research on Student-centered Evaluation Index System of Classroom Teaching in higher education [J]. Education Exploration, 2015(10):19-23.

[17] Qiu Wenjiao, Zhao Guang, Lei Wei. Construction of the University Inquiry-based Teaching Evaluation System Based on the Analytic Hierarchy Process [J]. Research in Higher Education of Engineering, 2016(6):138-143.

[18] YANG Huaizhong. Research on Engineering Ethics Education Model for Engineering College Students [J]. Higher Education Development and Evaluation, 2016, 32(4):73-79.

\section{$7 \quad$ Authors}

Jingmin Yang is a Chinese computer scientist, engineering educator, and senior en-gineer at Minnan Normal University of Computer Science, 36 Xianqianzhi Road, Xiangcheng District, Zhangzhou, 363000, P. R. China. He worked for ten years in Ruijie Network Co., Ltd., Which is famous for producing network devices, and is engaged in the development of network devices.

Trong-Yen Lee is a full professor of National Taipei University of Technology and is a dean of the Department of Electronic Engineering, Zhongxiao E. Rd., Taipei 10608, China. His research interests include Hardware and Software Co-design, Embedded System and Chip System Architecture. E-Mail: tylee@ntut.edu.tw

Baoxing Chen is a full professor at Lab of Granular Computing, member of Key Laboratory of Data Science and Intelligence Application and also is a vice-dean of the Computer School of Minnan normal university, who is in charge of teaching. His major research interest includes computer network and Algorithm design.

Wenjie Zhang is a full professor at Minnan normal university and a member of Key Laboratory of Data Science and Intelligence Application, Zhangzhou, China. His research interests include Cognitive Radio Network, Wireless Communications and Networks.

Article submitted 2019-06-16. Resubmitted 2019-07-27. Final acceptance 2019-07-29. Final version published as submitted by the authors. 